\title{
Angiosarcoma developing around a foreign body
}

\author{
JOHN HAYMAN, HUGO HUYGENS \\ From the Gippsland Base Hospital, Sale, Victoria, 3850, Australia
}

SUMMARY An 86-year-old World War I veteran developed an angiosarcoma at the site of a war wound. The tumour developed in relation to one of several metal grenade fragments. The tumour cells have been shown to contain blood coagulation factor VIII antigen and have features of endothelial cells on electron microscopy. The patient is claimed to be the last soldier dying of wounds sustained during that war, and to have the longest disease-free interval between injury and the onset of complications.

The third Ypres offensive in Flanders during World War I lasted for three months, comprised a total of eleven great attacks, and resulted in a British loss of 400000 killed or injured. Included in this number were 38000 Australian and New Zealand casualties. ${ }^{1}$ The patient was aged 21 yr when he was hit by fragments from a German stick grenade, during the battle of Passchendaele in October 1917. The wound was treated in a field hospital and many fragments removed, but some remained. The wound healed and on returning home, he worked as a house builder until his retirement. He remained well until June 1980, when he was 84 yr. Throughout his life he neither smoked nor drank. There was no history of exposure to arsenic, vinyl chloride, thorium compounds or $x$-ray therapy.

\section{Case report}

One week before admission to hospital, he noticed aching pain and swelling in the right axilla, which increased in severity. This was considered to be an abscess developing at the site of the old injury, and was locally excised.

An irregular portion of tissue, $4.5 \mathrm{~cm}$ in its greatest diameter, was removed. This consisted of fat and fibrous tissue, with areas of haemorrhage, apparent granulation and tissue necrosis. Within one necrotic area was a roughly triangular metal fragment, 0.5 $\mathrm{cm}$ across, and weighing $0 \cdot 8 \mathrm{~g}$. Histological examination of the specimen showed angioformative tumour tissue, with tumour cells arranged to form cords and trabeculae and in other areas lining spaces containing red blood cells (Fig. 1). The tumour cells had vesicular open nuclei, with prominent nucleoli, and

Accepted for publication 1 November 1982 showed moderate mitotic activity. There were extensive areas of tumour necrosis, stromal haemorrhage and infiltration by polymorphonuclear neutrophils and macrophages. Iron stain showed iron, both in tumour and stromal cells. The tumour was not encapsulated, but had a poorly defined margin, and infiltrated the tissue spaces. It was difficult to determine actual tumour margins for there was a blending between tumour and reactive blood vessels. Sections were stained using the immunoperox-

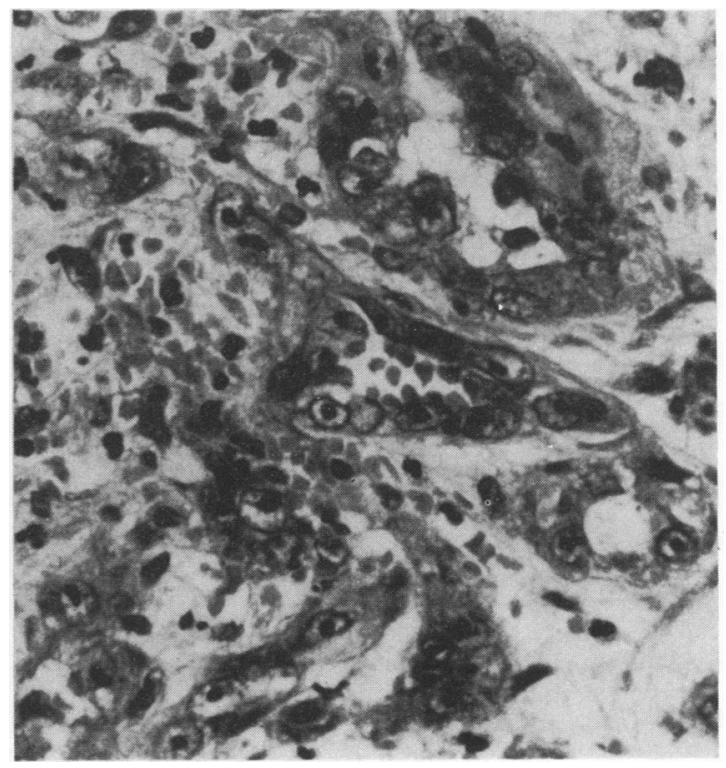

Fig. 1 Photomicrograph of the tumour, showing irregular vascular spaces, some containing red blood cells lined by tumour endothelial cells. Haematoxylin and eosin $\times 300$ 


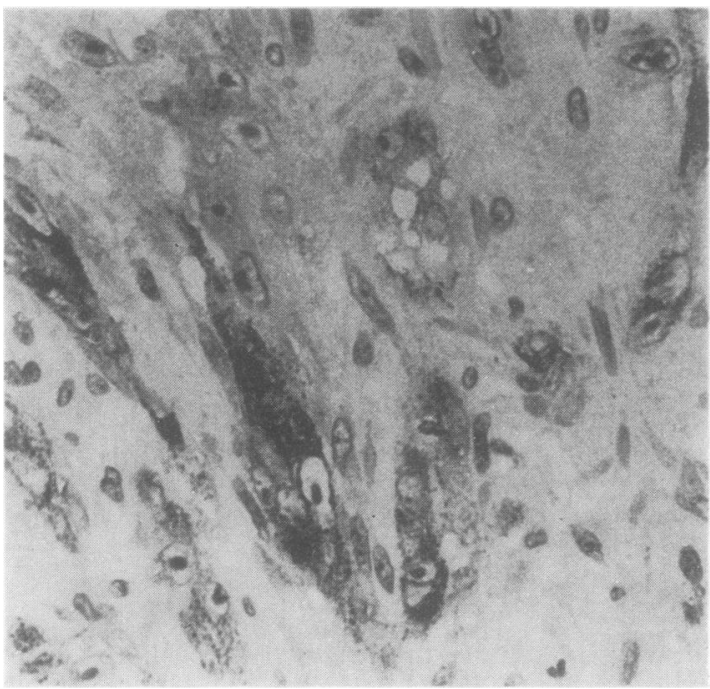

Fig. 2 Immunoperoxidase stain with factor VIII antibody, showing presence of factor VIII antigen in tumour cells. Peroxidase antiperoxidase $\times 300$

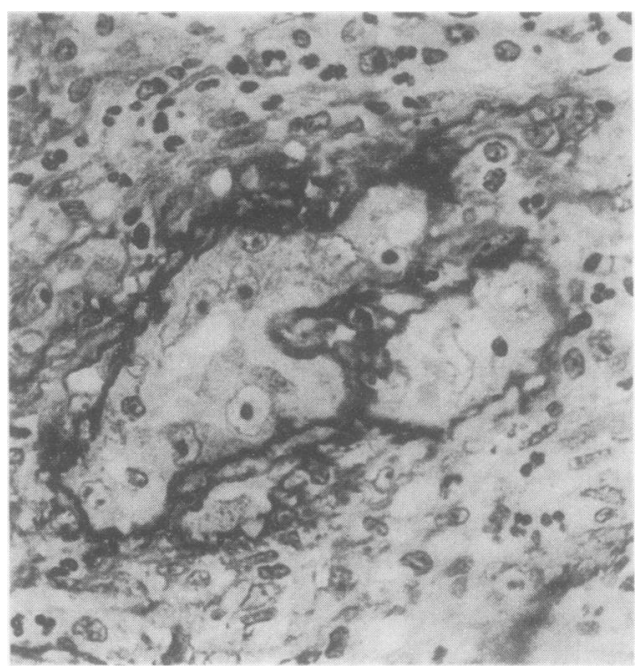

Fig. 3 Immunoperoxidase stain with factor VIII antibody, showing presence of factor VIII antigen in tumour basement membrane. Peroxidase antiperoxidase $\times 300$

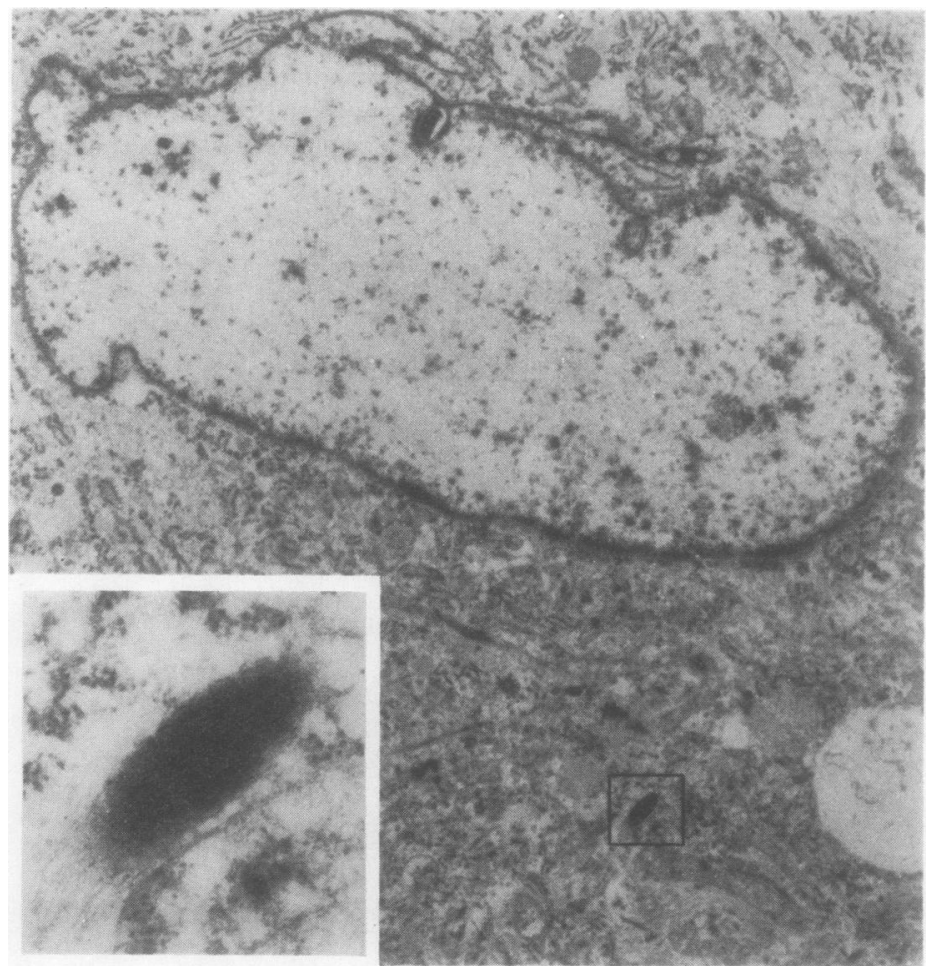

Fig. 4 Tumour cell nucleus, with a Weibel-Palade body visible as a linear electron dense streak in the cytoplasm below $\times 7400$

Insert: Weibel-Palade body with parallel microfilaments $\times 45000$ 
idase method (PAP) to identify blood coagulation factor VIII antigen. In some areas of the tumour this was demonstrated within tumour cells (Fig. 2) and in other areas it was associated with tumour basement membrane (Fig. 3). Factor VIII may be demonstrated in normal tissue endothelial cells, ${ }^{2}$ and is produced by endothelial cells in culture. ${ }^{3}$ Analysis of the metal fragment by direct emission spectrography showed the presence of iron only.

The patient was discharged from hospital, apparently well, with a healing wound, four days after operation. Two months later the mass had recurred, and was again excised with an appropriately wide margin. The excision included an ellipse of skin, 10 $\mathrm{cm} \times 2.5 \mathrm{~cm}$. The recurrent tumour appeared similar to the original biopsy, and electron microscopy of the tumour cells showed infolding and delicate protrusions of nuclear membrane, some basement membrane formation, pinocytotic vesicles, and the presence of occasional Weibel-Palade bodies, thus resembling normal endothelial cells ${ }^{4-6}$ (Fig.4). Electron probe analysis of the tumour tissue showed iron only, probably related to haemosiderin. Further recurrences developed, despite a third, wide excision and skin graft. He was treated with chemotherapy, (vincristine, adriamycin and cyclophosphamide) with initial improvement. However, he developed recurrent right-sided haemorrhagic pleural effusions and a persistent sinus in the right chest wall. His condition gradually deteriorated and he died in April 1982 aged 86 yr, nearly two years after the initial diagnosis, and 65 years after wounding.

Post-mortem examination showed the body of an emaciated male, with an irregular ulcer, approximately $8 \mathrm{~cm} \times 4 \mathrm{~cm}$, on the right side of the chest, penetrating the chest wall and exposing rib. Adjacent to this ulcer were surgical scars and extensive induration of the chest wall. Beneath this area, haemorrhagic and necrotic tumour tissue extended through to the pleural cavity, which contained $\mathbf{8 0 0}$ $\mathrm{ml}$ of heavily blood-stained fluid. Towards the apex, the right lung was adherent to the chest wall, but elsewhere it was collapsed and areas of pneumonic consolidation were present on both sides. The trachea and bronchi of both sides contained pus. Other abnormalities were extensive atherosclerosis of aorta and large arteries, with calcification, and atherosclerotic occlusion of the anterior interventricular coronary artery, with fibrosis of the anterior left ventricular wall. A second metallic fragment was obtained, lying against the fourth rib laterally, and analysis of this showed also iron only. Histological examination showed tumour tissue similar to the previous biopsies, bronchopneumonia, myocardial fibrosis and congestion of other organs. The second metallic fragment was separated from intercostal muscle by dense avascular fibrous tissue.

\section{Discussion}

Foreign body tumourigenesis has been extensively studied in animals, and these findings have been reviewed by Brand. ${ }^{7}$ It has been shown that rats regularly develop sarcomas following intraperitoneal or subcutaneous implantation of plastics. Attempts to incriminate chemical components or contaminants of the foreign body have failed, and it is concluded that the physical presence of the implant alone is responsible for tumourigenesis. Test materials lost their tumourigenic properties when implanted in pulverised or shredded form, or when their surface continuity was interrupted by multiple perforations. Additional support for the non-chemical nature of foreign body tumour production was obtained through the use of implant materials which could be considered non-reactive. These included special glasses, quartz, gold, platinum, stainless steel and other inert elements. Any of these materials proved to be tumourigenic when implanted in mice or rats, provided the surfaces were intact and continuous. When these surfaces were roughened or softened, tumour incidence decreased markedly. Formation of a fibrous capsule around the foreign body was essential for tumour formation. A rough surface was associated with a more prolonged cellular reaction, and delay in the formation of a fibrous capsule.

In our patient the exact relation of tumour to foreign body could not be determined, as the metallic fragment recovered in the initial biopsy was lying in a necrotic area. However, the fragment obtained at post-mortem was enclosed in a dense fibrous capsule, and closely adherent to rib.

The most common foreign body induced tumour in laboratory animals is a sarcoma, identified usually as a fibrosarcoma, spindle cell or anaplastic sarcoma. Several additional varieties of soft tissue neoplasms have been reported less frequently, including haemangiosarcoma. Foreign body induced tumours of all types in animals may arise from vascular tissue remaining and compressed in the fibrous area, sequestrated from immune surveillance.

Foreign body induced tumours in man are extremely rare. Fehrenbacher et al described an angiosarcoma of the aorta, arising near a Dacron aortic graft, 12 years after the graft was inserted. ${ }^{8}$ They reviewed three other cases in the literature, one of which developed only three months after insertion, and another which developed three years later in a patient who had been exposed to vinyl 
chloride and who had received immunosuppressive therapy.

"Granulation tissue sarcoma", developing in a patient with long-standing varicose ulceration, has been described by Dawson amd McIntosh. ${ }^{9}$ The patient had recurrent leg ulceration over a period of 10 years. The histology of this case appears similar to our present case, but the patient developed widespread metastases.

The pathogenesis of our patient's tumour is unresolved. The tumour may have arisen from sequestrated vascular elements in fibrous tissue surrounding inert foreign material, similar to the animal model. It may have arisen within long-standing granulation tissue around one particular fragment, as in the case described by Dawson and McIntosh, although another particle examined at post-mortem was surrounded by avascular fibrous tissue only. The tumour may have arisen from impurities diffusing from the fragments, such as arsenic, although no such elements were detected in analysis of the fragments, or in analysis of fragments obtained from an intact grenade. The association of tumour with the fragments may, of course, be purely coincidental, although this would appear unlikely. No other source of tumour was found at postmortem, and a careful search was made of all organs.

Knox and Wilkinson reported the development of a fluctuant abscess in the chest wall of a man also wounded by shrapnel in $1917 . .^{10}$ Their patient developed symptoms 62 years after wounding, and in their letter the authors imply that their case has the longest interval recorded between wounding and development of symptoms. Our patient, with a disease-free interval of 65 years, must also be one of the last soldiers dying from wounds sustained during the First World War.
Dr RA Sinclair, Alfred Hospital, Melbourne, prepared the immunoperoxidase sections with anti fac- 으 tor VIII antibody. Professor GB Ryan, Department of Anatomy, University of Melbourne, examined and photographed the electron microscope sections prepared in the Department of Pathology, St Vincent's Hospital, Melbourne. The Curator, Australian War Memorial, Canberra, provided the $\triangle$ history of the 3rd Ypres campaign, photographs of $\nRightarrow$ weapons and fragments for comparative analysis. $\vec{\circ}$ Mrs L McNaughton typed the manuscript.

\section{References}

1 Bean CEW. Anzac to Amiens. Canberra: Australian War Memorial, 1948.

${ }^{2}$ Hoyer WL, de los Santos RP, Hoyer JR. Antihaemophilic factor $ن$ antigen: localisation in endothelial cells by immunofluorescent $c$ microscopy. J Clin Invest 1973;52:2737-44.

${ }^{3}$ Jaffé EA, Hoyer LW, Nachman RL. Synthesis of antihaemophilic factor antigen by cultured endothelial cells. $J$ Clin Invest 1973;52:2757-64.

4 Rosai J, Sumner HW, Kostianovsky M, Perez-Mesa C. Angiosarcoma of the skin; a clinicopathological and fine structural study. Hum Pathol 1976;7:83-109.

5 Weibel ER, Palade GE. New cytoplasmic components in arterial endothelia. J Cell Biol 1964;23:101-12.

- Ghadially FN. Ultrastructural pathology of the cell. London: Butterworths, 1977:2-3.

${ }^{7}$ Brand KG, Janson, KH, Buoen LC. Foreign body tumourigenesis. CRC Crit Rev Toxicol 1976;4:353-94.

${ }^{8}$ Fehrenbacher JW, Bowers W, Strate R, et al. Angiosarcoma of the aorta associated with a dacron graft. Ann Thorac Surg $1981 ; 32: 297-301$.

9 Dawson EK, McIntosh D. Granulation tissue sarcoma following long-standing varicose ulceration. $J R$ Coll Surg (Edinburgh) 1971;16:88-95.

${ }^{10}$ Knox J, Wilkinson A. Shrapnel presenting with symptoms 62 years after wounding. Br Med J 1981;283:193.

Requests for reprints to: Dr John Hayman, Department of Pathology, Gippsland Base Hospital, Sale, Victoria, 3850, Australia. 